\title{
An expanded age range for meningococcal meningitis: molecular diagnostic evidence from population-based surveillance in Asia
}

\author{
Soon Ae Kim ${ }^{1 *+}$, Dong Wook Kim²,6† , Bai Qing Dong ${ }^{3}$, Jung Soo Kim ${ }^{4}$ Dang Duc Anh ${ }^{5}$ and Paul E Kilgore ${ }^{1,7}$
}

\begin{abstract}
Background: To understand epidemiologic patterns of meningococcal disease in Asia, we performed a retrospective molecular analysis of cerebrospinal fluid (CSF) specimens collected in prospective surveillance among children aged $<5$ years of age in China, South Korea, and Vietnam.

Methods: A total of 295 isolates and 2,302 CSFs were tested by a meningococcal species- and serogroup-specific polymerase chain reaction (PCR) assay targeting the Neisseria meningitidis ( $\mathrm{Nm}$ ) ctrA gene. Multi-locus sequence typing (MLST) was performed in Nm gene amplification analysis and incidence rates for meningococcal meningitis were estimated.

Results: Among 295 isolates tested, 10 specimens from Vietnam were confirmed as serogroup B and all were Sequence Type (ST) 1576 by MLST. Among the 2,032 CSF specimen tested, 284 (14\%) were confirmed by PCR (ctrA gene), including 67 (23.6\%) from China, 92 (32.4\%) from Korea, and 125 (44.0\%) from Vietnam. Neonates and infants aged $<6$ months of age accounted for more than 50\% of Nm-PCR positive CSF. Two CSF specimens from Vietnam were identified as serogroup B using MLST. In addition, 44 specimens underwent sequencing to confirm meningococcal serogroup; of these, 21 (48\%) were serogroup C, 12 (27\%) were serogroup X, 9 (20\%) were serogroup $\mathrm{Y}$ and $2(5 \%)$ were serogroup $\mathrm{B}$. The incidence rates of meningococcal meningitis among children $<5$ years of age was highest in Vietnam $(7.4 / 100,000$ [95\% Cl, 3.6 - 15.3] followed by Korea $(6.8 / 100,000$ [95\% Cl, 3.513.5] and China $(2.1 / 100,000)[95 \% \mathrm{Cl}, 0.7-6.2])$.

Conclusions: These results suggest that there is a previously undetected, yet substantial burden of meningococcal meningitis among infants and young children. Standardized, sensitive and specific molecular diagnostic assays with Nm serogrouping capacity are needed throughout Asia to understand the true burden of N. meningitidis disease.
\end{abstract}

Keywords: Cerebrospinal fluid, Meningococcal meningitis, Neisseria meningitidis, Serogroup, Surveillance

\section{Background}

Neisseria meningitidis ( $N$. meningitidis) is a gram-negative, encapsulated $\beta$-proteobacterium and the leading cause of epidemic meningitis. Globally, N. meningitidis causes an estimated 1.2 million cases and 135,000 deaths each year [1-3]. In Africa, N. meningitidis is the leading cause of severe, life-threatening meningitis and is responsible for thousands of cases and scores of deaths across sub-Saharan "meningitis belt" countries [4-7].

\footnotetext{
* Correspondence: sakim@ivi.int

${ }^{\dagger}$ Equal contributors

'Translational Research Division, International Vaccine Institute, SNU Research Park, San 4-8 Nakseongdae-Dong, Kwanak Gu, Seoul 151-919, South Korea Full list of author information is available at the end of the article
}

Moreover, N. meningitidis serogroups A and W-135 have been exported from Asia to other regions [8]. Previous studies suggest that these meningococcal serogroups were carried to the Middle East/Mediterranean region where meningococcal disease outbreaks subsequently occurred among Hajj pilgrims and across sub-Saharan African countries [4,9-12].

In Asia, meningitis outbreaks have been reported in child-care settings, schools, college dormitories, military camps, and among returning Hajj pilgrims [8,10,12-15]. Despite these reports documenting sporadic and epidemic meningococcal disease, there are large gaps in our knowledge of meningococcal disease patterns across

\section{Biomed Central}

(c) 2012 Kim et al.; licensee BioMed Central Ltd. This is an Open Access article distributed under the terms of the Creative Commons Attribution License (http://creativecommons.org/licenses/by/2.0), which permits unrestricted use, distribution, and reproduction in any medium, provided the original work is properly cited. 
large populations of Asia. It is believed that vaccine introduction against meningococcal disease may have been an important factor leading to the control of meningococcal epidemics [16,17], yet there is limited introduction of vaccines against meningococcal meningitis in Asian countries [13]. In addition, the serogroup distribution of meningococcus in Asia is scarce, in part, due to the limited availability of appropriate diagnostic tests including molecular assays $[13,18]$. Here, through the application of molecular analyses, we provide new evidence of meningococcal meningitis among hospitalized children $<5$ years of age who were identified during prospective, population-based surveillance in China, South Korea, and Vietnam.

\section{Methods}

\section{Study populations and surveillance}

In three study sites, prospective, population-based surveillance for invasive bacterial meningitis in children $<5$ years of age was conducted over a 2-year period. These sites were located in the Nanning, China (January 2001 December 2002), the Jeonbuk Province, South Korea (September 1999 - December 2001), and Hanoi, Vietnam (March 2000 - February 2002). In China, children residing in Nanning, Wuming and Yongning counties of the Guangxi Province were referred to one of six study hospitals if they had clinical signs and symptoms of bacterial meningitis. In Jeonbuk province, located in the southwestern region of South Korea, study sites included the provincial capital city of Jeonju and 10 districts within the province. In Vietnam, children who resided in any of the seven urban districts of Hanoi were referred to one of three central hospitals in Hanoi for study enrollment. Following specimen collection, cerebrospinal fluid (CSF) specimens were streaked on commercial blood agar culture media (Becton, Dickinson \& Co., Franklin Lakes, USA), incubated in $5 \% \mathrm{CO}_{2}$ at $37^{\circ} \mathrm{C}$ for 3 days and checked daily for bacterial growth. After completion of routine biochemical, hematological and microbiological tests, CSF specimens were preserved at $-70^{\circ} \mathrm{C}$ for further molecular analysis at the time surveillance conduction. Detailed methods for these standardized surveillance studies have been previously described [19-21]. For the analysis of specimens in this study, we utilized CSF specimens preserved from the previously conducted surveillance study [19-21]. All CSF specimens utilized in this study were de-identified prior to laboratory processing and analysis. In the context of the population-based surveillance study of meningitis conducted from 1999 to 2002, written consent was not obtained as the collection of CSF was considered routine standard of care for hospitalized children with suspected bacterial meningitis. For this reason, verbal consent of the parent or legal guardian present with the child during the hospitalization was recorded in the medical chart of the patient at the time of the clinical lumbar puncture procedure. This consenting procedure was approved by the local scientific ethical review committees of participating institutions. Ethical approvals for patient specimen collection during surveillance were obtained from the following institutions: International Vaccine Institute, Seoul, Korea; Harbor UCLA Medical Center, Torrance, CA, USA; Jeonbuk National University Hospital, Jeonju, Korea; Chonju Presbyterian Hospital, Jeonju, Korea; Namwon Medical Center, Namwon, Korea; Jeongeub Asan Foundation Hospital, Jeongeub, Korea; Won Kwan University Hospital, Iksan, Korea; National Institute of Hygiene and Epidemiology, Hanoi, Vietnam; National Institute of Pediatrics, Hanoi, Vietnam; St. Paul Hospital, Hanoi, Vietnam; Bach Mai Hospital, Hanoi, Vietnam and the Guangxi Zhuang Autonomous Region Center for Disease Control, Nanning, China.

\section{Laboratory testing}

The preserved, frozen CSFs and bacterial isolates that were collected during the prospective meningitis surveillance studies were used for the present analyses. Prior to molecular analysis of CSF specimens, isolates were subcultured to confirm the bacterial species present in each specimen. N. meningitidis identification and serogroup identification were conducted for all bacterial isolates using multiplex polymerase chain reaction (PCR) targeting the $c t r A$ gene [22]. PCR primers used for identification of three bacteria (S. pneumoniae, Haemophilus influenzae type b (Hib), and $N$. meningitidis) were $\operatorname{ctrA}$ primer sequences from Corless, et al. [23]. HinBF and HinBR primers for detection of $H$. influenzae type $\mathrm{b}$ using specific region of bexA gene were designed based on the report by Corless, et al. [23]. lytA primer sequences were modified based on a previous report by Llull, et al. [24]. PCR detection sensitivity of $\operatorname{ctr} A$ gene was validated by PCR reaction of serially-diluted reference DNA. Genomic DNA was prepared from bacterial culture as described previously [25] and DNA concentration was determined with a Nano Drop spectrophotometer. The genomic DNA prep concentration was adjusted to $100 \mathrm{ng} / \mu \mathrm{l}$ and seriallydiluted ten-fold to $1 \mathrm{pg} / \mu \mathrm{l}$. Based on the genome size of three serogroups of $N$. meningitidis (serogroup A, strain z2491: 2,184,406 bp, serogroup B: 2,272,351 bp, and serogroup C, strain FAM18: 2,194,961 bp), the molecular weight of a single copy of $N$. meningitidis genome was calculated as $2 \mathrm{fg} /$ one genome copy. Two microliters of each diluted reference DNA were used for template of the PCR reaction. $N$. meningitidis genomic DNA was purified from the bacterial cultures of $N$. meningitidis-confirmed isolates. The genomic DNA was further analyzed by two serogroup identification methods based on the $N$. meningitidis sialyltransferase (siaD) gene and serogroup-specific syn gene complex [22,26]. Primers used for serotyping of $N$. 
meningitidis A, B, C, Y, and W135 were designed at the International Vaccine Institute (Additional file 1: Table S1).

The CSF samples were processed as previously described [25]. Briefly, $200 \mu \mathrm{l}$ of each CSF sample was boiled for 3 minutes and then centrifuged for 5 minutes at $9,000 \times g$. The supernatant was removed and put into a new tube, and $2 \mu \mathrm{l}$ of the supernatant was used as the template in the $25 \mu \mathrm{l} \mathrm{PCR}$ reaction. $N$. meningitidis PCRs targeting the crgA, IS1106, and 16S rRNA genes were performed on all MLST-negative CSF specimens to identify additional $N$. meningitidis-positive CSF specimens. The established multi-locus sequence typing (MLST) scheme (http://pubmlst.org/neisseria/) for Neisseria spp. was used to analyze bacterial isolates and CSF specimens that were positive for $N$. meningitidis specific gene amplification analysis. $N$. meningitidis-specific gene amplification analysis of $N$. meningitidis PCR-positive CSF with the presence of contact-regulated gene A $(\operatorname{crgA})$, IS1106, and 16S rRNA was conducted.

\section{Data collection and statistical analysis}

For analysis of epidemiologic data, the original study surveillance database from each field site was merged with $N$. meningitidis laboratory results using a unique study identification number available for each patient. For age group analysis, patients were grouped into the following age strata: < 1, 1-6, 7-11, 12-23, 24-35, 36-47, and 48-59 months of age. Children with PCRconfirmed $N$. meningitidis were grouped to describe demographic characteristics, clinical signs and symptoms of meningitis, prior use of antibiotics and outcomes at discharge. Further analysis of results from $N$. meningitidis serogroup-specific PCR and sequencing results were used to describe patient distributions by clinical characteristics and month of admission. To estimate the incidence of serogrouped $N$. meningitidis, previously published population denominator data for children $<5$ years of age were applied for the calculations of incidence rates [19-21]. Ninety-five percent confidence limits for incidence rates were calculated using the Wilson score method [27]. Data analysis was performed using STATA (version 11.0, StataCorp LP, TX, USA).

\section{Results}

\section{Demographic and clinical characteristics}

A total of 2,327 specimens (295 isolates and 2,032 CSF) collected from children in China, 626 (26.9\%), Korea, $700(30.1 \%)$ and Vietnam, 1001 (43.0\%) were processed for nucleic acid testing. Male patients constituted 63.6\% of enrolled subjects. Among children aged $<5$ years, more than half $(n=1,392)$ were infants aged $<1$ year (including 332 who were $<1$ month of age, 772 aged 1-6 months, and 288 aged 7-11 months). Among 295 bacterial isolates, 10 isolates in Vietnam were confirmed as $N$. meningitidis. Of these, one patient was younger than one month old, one was 1-6 months of age, four were 7-11 months of age, and four patients were 12-35 months of age. Five of the cultureconfirmed patients were male and half were female. Among the 2,032 cerebrospinal fluid (CSF) specimens tested, $14 \%(\mathrm{n}=284)$ were confirmed by $N$. meningitidis PCR targeting the ctrA gene, including 67 patients (11.4\%) in China, 92 (13.2\%) in Korea, and 125 (14.2\%) in Vietnam. S. pneumoniae and Haemphilus influenzae type b (Hib) were identified as well (Table 1). Among those with $N$. meningitidis PCR-confirmed infection, 26 specimens (11 in China and 15 in Vietnam) could not be linked with the original clinical database due to missing variables, resulting in a total of 258 meningococcal meningitis patients with complete data available for further analysis.

Overall, the mean age of children with $N$. meningitidis PCR-confirmed meningitis was 14.4 ( \pm 17.7) months, with a mean age of 17.4 ( \pm 19.2$)$ months among females versus $12.6( \pm 16.5)$ months among in males $(P<0.05)$. For all countries combined with culture confirmed and PCR-confirmed, males accounted for 61.9\% $(n=166)$ and females were $38.1 \%(\mathrm{n}=102, P<0.05)$. Approximately half of the $N$. meningitidis PCR-confirmed patients were $<6$ months of age $(50.0 \%$ in China; $58.7 \%$ in Korea; and $47.3 \%$ in Vietnam), and more than threequarters $(75.6 \%)$ of them were young children aged $<2$ years old (Table 2 ).

Among patients who had PCR-confirmed meningitis, the mean length of their hospital stay was 8.2 days ( \pm 11.3 SD; median stay: 6 days). At the time of initial clinical presentation, patients exhibited severe manifestations of meningitis including both fever and sepsis (74\%; $\mathrm{n}=191)$, followed by seizure $(36.4 \% ; \mathrm{n}=94)$, vomiting $(33.0 \% ; \mathrm{n}=85)$, lethargy or coma $(34.0 \%$; $\mathrm{n}=$ 87 ), stiff neck (26.0\%; $\mathrm{n}=67)$, irritability or confusion $(20.5 \% ; n=53)$, and bulging fontanelle $(16.0 \% ; n=40)$ (Table 2). In Korea and Vietnam, the majority (87\% and $74.5 \%$, respectively) of PCR-confirmed $N$. meningitidis patients were found to have fever and sepsis upon initial presentation, while this was less frequent $(51.8 \%$; $n=29)$ in China. Seizures were notably more common among Chinese children $(53.6 \% ; \mathrm{n}=30)$ compared with either Korean $(14.1 \% ; \mathrm{n}=13)$ or Vietnamese $(46.4 \% ; \mathrm{n}=51)$ children. Overall, $17.4 \%(n=45)$ were hospitalized in the neonatal ward or intensive care unit $(5.0 \% ; n=13)$, which might have been caused by severe clinical signs and symptoms. Among the $N$. meningitidis PCRconfirmed children, five deaths were observed. Three deaths were identified in China within the early days of life: one was identified at three days of age, another one at one week of age, and one at 3.5 weeks 
Table 1 Cerebrospinal fluid analysis of simultaneous detection of bacteria by PCR

\begin{tabular}{lcccc}
\hline Bacteria & China & Korea & Vietnam & Total \\
\cline { 2 - 3 } & Number (\%) & Number (\%) & $41(4.7)$ & 97 \\
\hline S. pneumoniae & $27(4.6)$ & $29(4.2)$ & $38(5.5)$ & $146(16.6)$ \\
Haemophilus Influenzae type b & $12(2.0)$ & $92(13.2)$ & $125(14.2)$ & 196 \\
N. meningitidis & $67(11.4)$ & $538(77.1)$ & $566(64.5)$ & 284 \\
None Detected & $511(87.0)$ & $608(100)^{*}$ & $837(100)^{*}$ & 2032 \\
Total & $587(100)^{*}$ & & 1615
\end{tabular}

*30 (China), 89 (Korea), 41 (Vietnam) CSF specimens were positive for more than two bacterial species; **total number was subtracted 160 from 2192 that was more than two bacterial species among three countries.

of age. Two other deaths were identified in Vietnam, where death occurred at two days of age and at 22.3 months of age.

During the original prospective surveillance studies, over-the-counter use of antibiotics without a prescription was common in each country. In Vietnam, $70.9 \%$ of $N$. meningitidis PCR-confirmed patients reported antibiotic consumption prior to hospital admission, compared with $57.6 \%$ in Korea and $41.4 \%$ in China (overall consumption of antibiotics among the children with meningococcal

Table 2 Meningococcal meningitis among children aged < 60 months in China, Korea and Vietnam by age and gender group, 1999 through 2002*

\begin{tabular}{|c|c|c|c|c|c|}
\hline \multirow[t]{4}{*}{ Characteristics } & \multicolumn{3}{|c|}{ PCR-confirmed } & \multirow{4}{*}{$\begin{array}{c}\text { Culture-confirmed } \\
\text { Vietnam } \\
(n=10) \\
N(\%)\end{array}$} & \multirow{4}{*}{$\begin{array}{c}\text { Total } \\
\frac{(\mathrm{n}=268)^{\mathrm{b}}}{\mathrm{N}(\%)}\end{array}$} \\
\hline & China & Korea & Vietnam & & \\
\hline & $\overline{(n=56)}$ & $\overline{(n=92)}$ & $\overline{(n=110)}$ & & \\
\hline & N (\%) & N (\%) & N (\%) & & \\
\hline \multicolumn{6}{|l|}{ Age (months) } \\
\hline$<1$ & $17(30.4)$ & $28(30.4)$ & $23(20.9)$ & $1(10.0)$ & $69(25.7)$ \\
\hline $1-6$ & 11 (19.6) & $26(28.3)$ & $29(26.4)$ & $1(10.0)$ & $67(25.0)$ \\
\hline $7-11$ & $5(8.9)$ & $4(4.3)$ & $21(19.1)$ & $4(40.0)$ & $34(12.7)$ \\
\hline $12-23$ & $11(19.6)$ & $11(12.0)$ & $9(8.2)$ & $3(30.0)$ & $34(12.7)$ \\
\hline $24-35$ & $3(5.4)$ & $4(4.3)$ & $8(7.3)$ & $1(10.0)$ & $16(6.0)$ \\
\hline $36-47$ & $6(10.7)$ & $11(12.0)$ & $11(10.0)$ & 0 & $28(10.4)$ \\
\hline $48-59$ & $3(5.4)$ & $8(8.7)$ & $9(8.2)$ & 0 & $20(7.5)$ \\
\hline \multicolumn{6}{|l|}{ Gender } \\
\hline Female & $13(23.2)$ & $31(33.7)$ & $53(48.2)$ & $5(50.0)$ & $102(38.1)$ \\
\hline Male & $43(76.8)$ & $61(66.3)$ & $57(51.8)$ & $5(50.0)$ & $166(61.9)$ \\
\hline \multicolumn{6}{|l|}{ Clinical features } \\
\hline Lethargy/coma & 19 (33.9) & $8(8.7)$ & $60(54.5)$ & $4(40.0)$ & $91(34.0)$ \\
\hline Irritability/confusion & $17(30.4)$ & $7(7.6)$ & $29(26.4)$ & $4(40.0)$ & $57(21.3)$ \\
\hline Nuchal rigidity & $17(30.4)$ & $7(7.6)$ & $43(39.1)$ & $6(60.0)$ & $71(26.5)$ \\
\hline Seizure & $30(53.6)$ & $13(14.1)$ & $51(46.4)$ & $4(40.0)$ & 98 (36.6) \\
\hline Vomiting & $3(5.4)$ & 18 (19.6) & $64(58.2)$ & $7(70.0)$ & $92(34.3)$ \\
\hline Bulging fontanelle & $8(14.3)$ & $1(1.1)$ & $31(28.2)$ & $2(20.0)$ & $42(15.7)$ \\
\hline Fever or septic appearance & $29(51.8)$ & $80(87.0)$ & $82(74.5)$ & $9(90.0)$ & $200(74.6)$ \\
\hline \multicolumn{6}{|l|}{ Outcome } \\
\hline Alive & $53(94.6)$ & UK & UK & $8(80.0)$ & NA \\
\hline Deceased & $3(5.4)$ & UK & UK & $2(20.0)$ & NA \\
\hline \multicolumn{6}{|l|}{ Prior antibiotic usage } \\
\hline Yes & $23(41.1)$ & $53(57.6)$ & 78 (70.9) & $10(100.0)$ & $164(61.2)$ \\
\hline
\end{tabular}


disease in the three sites including culture-confirmed patients, $61.2 \%[164 / 258])$.

\section{Incidence rates}

The incidence rates of $N$. meningitidis by culture and serogroup-specific PCR and sequencing was highest in Vietnam at 7.4/100,000 population (95\% CI, 3.6-15.3), followed by Korea 6.8/100,000 (95\% CI, 3.5-13.5) and China 2.1/100,000 (95\% CI, 0.7-6.2) (Table 3). In China and Korea, age-specific incidence rates were highest in children aged $<6$ months, whilst in Vietnam, rates were highest in those aged $<12$ months. Of these, there was a particularly high incidence rate of meningococcal meningitis among very young infants aged less than one month of age: in China, Korea, and Vietnam incidence was 96/100,000 (95\% CI, 29.7-309.4), 81.5/100,000 (95\% CI, 18.8-352.2), and 36.2/100,000 (95\% CI, 3.8-346.0), respectively. Consequently, the incidence rate was highest in children during the first year of life in all three countries (Table 3).

With respect to monthly distributions, we found that $N$. meningitidis cases increased during May through August in China and peaked sharply from March to June in Vietnam. In Korea, the number of $N$. meningitidis cases was highest from February through April (data not shown).

\section{PCR results and serogroup}

All 10 meningococcal serogroup B among isolates originated from Vietnam and two CSF specimens from Vietnam contained the allele type 140, 5, 9, 173, 175, 34, 165 (in the order $a b c Z, a d k$, aroE, fum $C, g d h, p d h C$, and pgm), which has been designated as sequence type (ST) 1576 (Additional file 1: Tables S2 and S3). CSF specimens that were $N$. meningitidis PCR-positive for ctrA and positive for serogroup identification by $\mathrm{PCR}$, but negative by MLST were further analyzed by PCR for the presence of $\operatorname{crgA}$, IS1106, and $N$. meningitidis specific $16 \mathrm{~S}$ rRNA.

A total of $44 N$. meningitidis PCR-positive CSF were serogrouped, but one did not link to clinical data, resulting in 43 specimens with complete serogroup and clinical information available for further analysis. Of these, 20 (91\%) CSFs from Vietnam were found to have $N$. meningitidis serogroup $\mathrm{C}$, and two (9\%) were positive for serogroup $\mathrm{B}$. In contrast, serogroups $\mathrm{X}$ and $\mathrm{Y}$ were prevalent in China (50\% [n=3] X and 33\% Y $[n=2])$, while serogroup $X$ comprised $56 \%[n=9]$ and serogroup $\mathrm{Y}[\mathrm{n}=6]$ comprised $38 \%$ in Korea (Table 4). Eighty-four percent of the CSF specimens that were positive by the $N$. meningitidis PCR targeting the ctrA gene could not be serogrouped. Among the 43 children with $N$. meningitidis PCR-positive CSF and complete demographic data, $48.8 \% \quad(n=21) \quad$ were less than six months of age (Figure 1). In China, among the 6 children whose specimens could be serogrouped, five were less than one month of age and one was $<12$ months of age. Among the $16 N$. meningitidis PCR-positive Korean children whose specimens could be serogrouped, seven were $<6$ month of age and two were $<2$ years of age, and the remaining seven were older than two years of age. In Vietnam, of the $21 N$. meningitidis PCR-positive and serogrouped children, five were $<1$ month of age, four were 1-6 months of age, five were $<12$ months of age, and seven children were older than one year of age (Figure 1).

Further analyses were conducted. Two serogroup B positive CSF specimens in Vietnam also showed positive results in $N$. meningitidis MLST analysis. However, the $43 N$. meningitidis ctrA positive CSF specimens that were also positive by serogrouping PCR assay showed negative results in the $N$. meningitidis MLST. Among the $20 \mathrm{~N}$. meningitidis serogroup $\mathrm{C}$ positive CSF specimens collected in Vietnam, 16 were positive for $\operatorname{crgA}$ detection, 5 were positive for IS1106 detection, and 2 showed positive results in detection of $16 \mathrm{~S}$ rRNA (Additional file 1: Table S2).

\section{Discussion}

This is the first and largest collection of CSF specimens obtained during population-based studies in representative populations of Asian children that provides

Table 3 Incidence of meningococcal meningitis by culture $(n=10)$ and serogroup-specific PCR and sequencing $(n=43)$

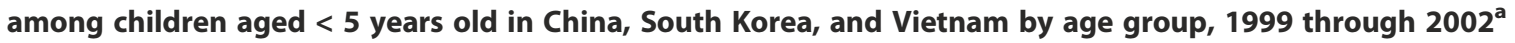

\begin{tabular}{|c|c|c|c|c|c|c|}
\hline \multirow{2}{*}{$\begin{array}{l}\text { Age } \\
\text { (months) }\end{array}$} & \multicolumn{2}{|r|}{ China } & \multicolumn{2}{|r|}{ Korea } & \multicolumn{2}{|r|}{ Vietnam } \\
\hline & $\mathbf{N}$ & Incidence rate $(95 \% \mathrm{Cl})$ & $\mathbf{N}$ & Incidence rate $(95 \% \mathrm{Cl})$ & $\mathbf{N}$ & Incidence rate $(95 \% \mathrm{Cl})$ \\
\hline$<6$ & 5 & $14.6(4.5-47.2)$ & 7 & $27.2(9.9-74.2)$ & 11 & $15.5(3.6-67.2)$ \\
\hline $7-11$ & 1 & $3.4(0.4-33.0)$ & 0 & 0 & 9 & $29.1(8.0-106.0)$ \\
\hline $12-23$ & 0 & 0 & 2 & $4.5(0.8-25.8)$ & 5 & $13.7(3.8-50.1)$ \\
\hline $24-59$ & 0 & 0 & 7 & $4.8(1.8-13.1)$ & 6 & $2.4(0.5-10.2)$ \\
\hline overall & 6 & $2.1(0.7-6.2)$ & 16 & $6.8(3.5-13.5)$ & 31 & $7.4(3.6-15.3)$ \\
\hline
\end{tabular}

a Surveillance periods: China, January 1, 2000--December 31, 2002; South Korea: September 1, 1999--December 31, 2001; Vietnam: March 4, 2000-March 3, 2002

bIncidence rates are shown per 100,000 children; $95 \%$ confidence intervals are shown in parentheses. 
Table 4 Serogroup distributions of $\boldsymbol{N}$. Meningitidis among Cerebrospinal fluid specimens and bacterial isolates among children aged $<5$ years old in China, South

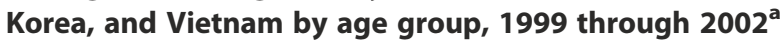

\begin{tabular}{|c|c|c|c|c|}
\hline \multirow[t]{3}{*}{ Serogroup } & \multicolumn{3}{|c|}{ Cerebrospinal fluid } & \multirow{3}{*}{$\frac{\frac{\text { Bacterial isolates }}{\text { Vietnam }}}{\mathrm{N}(\%)}$} \\
\hline & China & Korea & Vietnam & \\
\hline & & N (\%) & & \\
\hline A & 0 & 0 & 0 & 0 \\
\hline B & 0 & 0 & $2(9.1)$ & $10(100)$ \\
\hline C & 0 & $1(6.3)$ & $20(90.9)$ & 0 \\
\hline W-135 & $1(16.7)$ & 0 & 0 & 0 \\
\hline$x$ & $3(50.0)$ & $9(56.3)$ & 0 & 0 \\
\hline Y & $2(33.3)$ & $6(37.5)$ & 0 & 0 \\
\hline Total & $6(100)$ & $16(100)$ & $22(100)^{b}$ & $10(100)$ \\
\hline
\end{tabular}

${ }^{a}$ Surveillance periods: China, January 1, 2000--December 31, 2002; South Korea: September 1, 1999--December 31, 2001; Vietnam: March 4, 2000-March 3, 2002. ${ }^{\mathrm{b}}$ One specimen could not be linked with the clinical database.

laboratory-confirmed meningococcal meningitis incidence rates based on molecular diagnostic technologies. The application of modern molecular diagnostics for $N$. meningitidis identified case clusters of meningococcal serogroup $B$ meningitis and an additional high number of serogroup $\mathrm{X}$ and $\mathrm{Y}$ meningococcal meningitis that had been previously unrecognized when CSFs were tested only by culture and antigen detection methods alone during the original surveillance study periods. Our findings suggest that retrospective molecular analyses of well-preserved clinical specimens in a biorepository provide novel insights into causes of childhood meningitis that are potentially vaccine-preventable diseases, particularly among patients who may commonly use antibiotics.

Based on the combined testing of CSFs by bacterial culture and PCR, this study demonstrated that $75.6 \%$ of the children identified with $N$. meningitidis in CSF were less than 2 years of age: this occurred particularly among infants less than 6 months of age and even in neonates. Previous incidence studies of N. meningitidis among children have demonstrated a sizable disease burden. For example, among children under 4 years of age in the United Kingdom [28], rates of serogroup B meningococcal infections peaked among infants aged less than one year of age with, accounting for almost $90 \%$ of laboratory confirmed cases. There is still no licensed vaccine available to protect against serogroup B disease and Active Bacterial Core surveillance (ABCs) data in the United States estimated that infants aged $<1$ year had the highest rates of meningococcal disease at 5.38 cases per 100,000 population in 1998-2007 [29]. In Romania, children aged $<5$ years old were found to have a meningococcal meningitis incidence rate of 22 per 100,000 annually based on prospective populationbased surveillance in 2000-2002 [30].

In spite of reports of sporadic or outbreak-associated meningococcal disease in Asia, there are limited data on meningococcal incidence rates and on N. meningitidis serogroup distribution. In Korea, there is an estimated annual incidence of 2.2 per 100,000 among 550,000 soldiers [14]; a nationwide study among 17 university hospitals also reported bacteria-proven meningococcal meningitis in 125 cases from 1996 to 2005 . Of these, two (1.6\%) were less than one month of age [31]. Available study identified

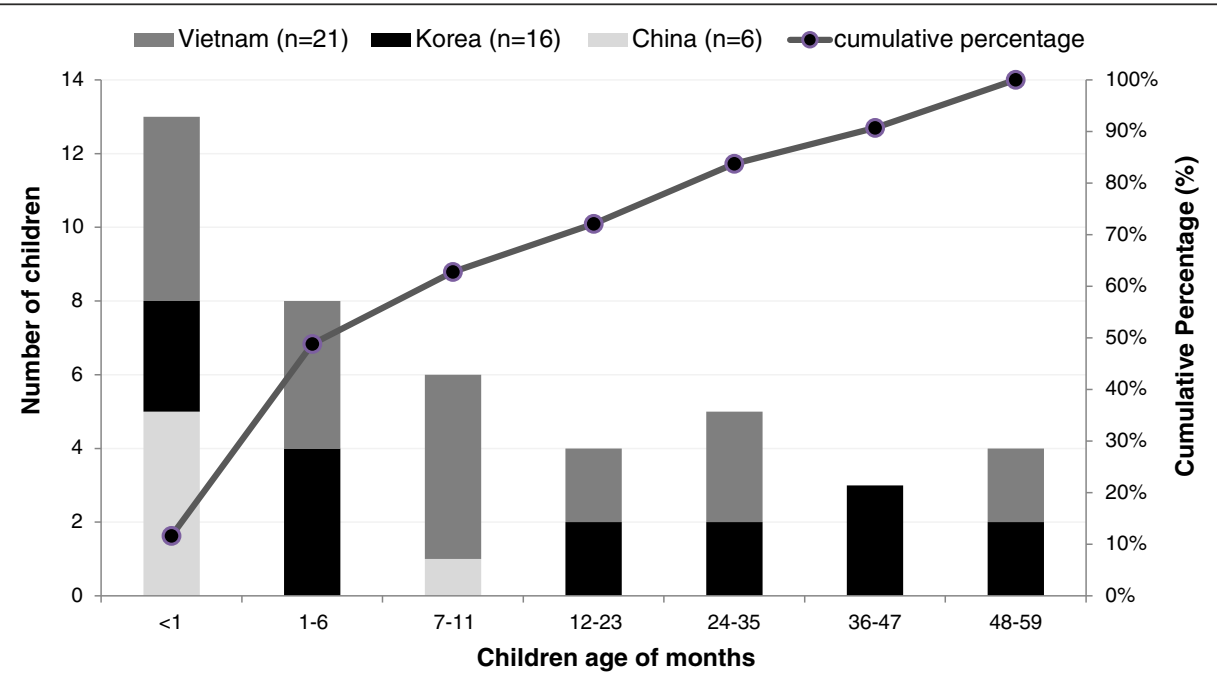

Figure 1 Number and cumulative percentage of meningococcal meningitis from PCR confirmation with ctrA gene by age group among children aged $<5$ years old in China, South Korea, and Vietnam by age group, 1999 through $2002{ }^{\text {a }}{ }^{a}$ Surveillance periods: January 1, 2000-December 31, 2002, China; September 1, 1999-December 31, 2001 (4-month hiatus, August to November 2000), Korea; March 4, 2000-March 3, 2002, Vietnam. 
outbreaks of $N$. meningitidis in southern province in Vietnam [32].

Our findings describing the meningococcal serogroup distribution are inconsistent with previous studies. For example, there have been no reports on serogroup $\mathrm{X}$ in Asia in the past 50 years [13]. There is also a recent increase in serogroup $\mathrm{B}, \mathrm{C}$, and $\mathrm{Y}$ predominating in Europe, the United States, and Australia, whilst serogroup A is prevalent in Africa and Asia [12,13,33]. All of the bacterial isolates in Vietnam from our analysis were serotype $\mathrm{B}$, which is the most commonly identified serogroup in infants in endemic settings. Prolonged outbreaks of serogroup B disease in some countries have also caused substantial morbidity and mortality [34,35] and there is presently no available vaccine against this serogroup $[2,30,36]$. The occurrence of a cluster of serogroup $\mathrm{B}$ meningococcal meningitis in Vietnam underscores the need for further investigation of epidemiologic factors and transmission dynamics that drive circulation of meningococcal serogroups. In addition, a substantial number of serogroup $\mathrm{X}$ and $\mathrm{Y}$ in China and Korea was identified in the present study, suggesting that serogroup $\mathrm{X}$ may have been previously under-detected due to limited surveillance or limited availability of assays capable of detecting serogroup X. Among the three countries, N. meningitidis was responsible for very large epidemics in China, leading to the development and introduction of serogroup $\mathrm{A}$ and C meningococcal polysaccharide vaccines for children starting in the 1980s [37]. Nonetheless and in spite of the vaccine having been introduced in China, there have been sporadic outbreaks and increased cases of circulating serogroup A and C infections in 2003-2006 [38]. There have also been continuous reports of serogroup B infections, which have been confirmed with modern molecular diagnostics [37-39]. In Korea, our results showed a unique serogroup distribution (serogroup X [9/16], Y [6/16] and C $[1 / 16])$, relative to a previous study that reported serogroup $\mathrm{Y}$ as the most frequently detected serogroup (9/11 isolates). Another study found one serogroup A and two serogroup C strains among ten $\mathrm{crg}$ A PCR positive specimens $[14,40]$. Current available vaccines target serogroups A, B, C, and W-135 [12,41], but do not cover serogroups $\mathrm{X}$ and $\mathrm{Y}$. The results from our analysis suggest that existing knowledge gaps may be filled through the application of systematic surveillance that applies molecular diagnostic techniques for detection of $N$. meningitidis. The application of molecular testing for meningococcus has had a substantial impact in our understanding epidemiologic patterns of meningococcus in Asia and the potential role of contemporary available meningococcal vaccines.

Clinically, our CSF analysis confirms that infants and young age groups were particularly vulnerable to meningococcal meningitis, suffering severe signs and symptoms, including sepsis, seizure, coma and lethargy, and vomiting.
Our findings are intriguing given the limited number of previous studies that have reported $N$. meningitidis infection in neonates and young infants $[33,42,43]$. These new results suggest the need to improve surveillance for meningitis among infants and to consider the role of meningococcal vaccines among infants [12,41].

Although this study provides one of the largest CSF analyses to describe N. meningitidis in Asian countries, there are some limitations. For example, $84.1 \%$ of the $N$. meningitidis positive CSF specimens could not be serogrouped and may have resulted from partial degradation of pathogen components during storage. In addition, some specimen testing may have been limited by prolonged storage that was associated with diminution of specimen volume through evaporation or prolonged storage. Second, although original studies were done in representative populations, rates of meningococcal meningitis among children in other parts of each country and in other countries in Asia may differ from those found in this analysis. Third, overall reduced detection of bacterial pathogens, including common invasive species causing meningitis in children, may, at least in part, be the result of widespread antibiotic overuse that was observed throughout each study site in China, Korea and Vietnam. In spite of the easy access to antibiotics in these three countries, an $11.6 \%$ fatality prevailed and remains poorly understood.

\section{Conclusions}

The burden of $N$. meningitidis-associated meningitis among Asian children aged $<5$ years old was found to be substantially higher than previously reported. Incidence rates among neonates and infants suggest that meningococcal meningitis may be affecting a younger age range of patients than previously understood. By understanding the dynamics of $N$. meningitidis, with incorporation of routine PCR methods for detection of $N$. meningitidis and the use of standardized surveillance methods for meningococcal meningitis, many countries will have the capacity to more accurately describe and mitigate invasive meningococcal disease. This may be of patients particularly true in areas with high antimicrobial usage in developing or middle income countries, where laboratory culture capacity may be limited. To date, more than a decade after the original prospective surveillance studies were completed, there have been few improvements in surveillance for $N$. meningitidis across Asia. In addition, given these observations, it is likely that new surveillance may uncover additional serogroups, including those identified in the results presented here. Therefore, we strongly advocate for a pan-Asian surveillance strategy focused on meningococcal meningitis to better understand the epidemiology and to implement prevention strategies (e.g., vaccines) in this region. 


\section{Additional file}

Additional file 1: Table S1. Primers used for serotyping of $N$. meningitidis $\mathrm{A}, \mathrm{B}, \mathrm{C}, \mathrm{Y}$, and $\mathrm{W} 135(4)^{*}$. S2. Neisseria meningitidis identifications in CSF specimens, in China, South Korea, and Vietnam, 1999 through 2002. S3. Multi-locus sequence typing (MLST) results of 10 N. meningitidis isolates and 2 CSF specimens collected in Vietnam.

\section{Competing interests}

The authors declare that they have no competing interests.

\section{Authors' contributions}

SAK and PEK carried out study design, data collection and analysis, and drafted the manuscript. DWK performed study design and conducted molecular laboratory test and drafted the manuscript. BQD, JSK and DDA participated in its design and helped to draft the manuscript. All authors read and approved the final manuscript.

\section{Acknowledgements}

We thank Dr. Batmunkh Nyambat for his technical assistance in accessing patient and laboratory databases assembled for each of the prospective surveillance systems in China, Korea and Vietnam. We also thank Eunjin Kim for her technical assistance in the laboratory testing of the CSF and bacterial isolates at the IVI. We specially thank Dr. Mirna Robert- Du Ry van Beest Holle, Novartis Vaccines and Diagnostics, Global Epidemiology, The Netherlands, for epidemiologic insights and Dr. Maurizio Comanducci, Laboratory Head, Novartis Vaccines and Diagnostics, for his inputs on particular laboratory tests and interpretations. We thank Drs. Kenneth Zangwell and Swei-Ju Chang for their collaboration in the preservation of CSF specimens. We thank the Communications \& Advocacy Unit at IVI for editorial review and Lisa DeTora, at the Medical Publication Lead in Novartis Vaccines and Diagnostics, for her editorial comments during preparation of this manuscript.

\section{Financial support}

This work was supported by an unrestricted funding to the International Vaccine Institute from the government of South Korea, and Sweden. Additional support for this project was provided by Novartis Vaccines and Diagnostics, Global Epidemiology, The Netherlands. Results reported in this manuscript were presented in part at The 7th World Congress of the World Society for Pediatric Infectious Diseases (WSPID), Melbourne, Australia. November 16-19, 2011

\section{Author details}

${ }^{1}$ Translational Research Division, International Vaccine Institute, SNU Research Park, San 4-8 Nakseongdae-Dong, Kwanak Gu, Seoul 151-919, South Korea. ${ }^{2}$ Laboratory Science Division, International Vaccine Institute, Seoul, South Korea. ${ }^{3}$ Guangxi Zhuang Autonomous Region Center for Disease Control \& Prevention, Nanning, China. ${ }^{4}$ Department of Pediatrics, Jeonbuk National University Hospital, Jeonju, South Korea. ${ }^{5}$ National Institute of Hygiene and Epidemiology, Hanoi, Vietnam. ${ }^{6}$ Department of Pharmacy, College of Pharmacy, Hanyang University, Suwon, South Korea. ${ }^{7}$ Department of Pharmacy Practice, Eugene Applebaum College of Pharmacy \& Health Sciences, Wayne State University, Detroit, USA.

Received: 29 May 2012 Accepted: 5 November 2012 Published: 19 November 2012

\section{References}

1. Van Deuren M, Meis JF: Meningococcal disease. N Engl J Med 2001 345(9):699.

2. Stephens DS, Greenwood B, Brandtzaeg P: Epidemic meningitis, meningococcaemia, and Neisseria meningitidis. Lancet 2007 369(9580):2196-2210.

3. Tan LK, Carlone GM, Borrow R: Advances in the development of vaccines against Neisseria meningitidis. N Engl J Med 2010, 362(16):1511-1520.

4. Trotter $\mathrm{CL}$, Greenwood BM: Meningococcal carriage in the African meningitis belt. Lancet Infect Dis 2007, 7(12):797-803.
5. Chanteau S, Rose AM, Djibo S, Nato F, Boisier P: Biological diagnosis of meningococcal meningitis in the African meningitis belt: current epidemic strategy and new perspectives. Vaccine 2007, 25(Suppl 1):A30-A36.

6. Boisier P, Mainassara HB, Sidikou F, Djibo S, Kairo KK, Chanteau S: Casefatality ratio of bacterial meningitis in the African meningitis belt: we can do better. Vaccine 2007, 25(Suppl 1):A24-A29.

7. Hayward P: African meningitis belt: 2006. Lancet Neurol 2006, 5(5):389

8. Wilder-Smith A: W135 meningococcal carriage in association with the Hajj pilgrimage 2001: the Singapore experience. Int J Antimicrob Agents 2003, 21(2):112-115.

9. Meningococcal infection in pilgrims returning from the Haj: update. Commun Dis Rep CDR Wkly 2000, 10(17):149-152.

10. Meningococcal disease associated with the Haj-update. Commun Dis Rep CDR Wkly 2000, 10(19):169.

11. Galloway Y, Stehr-Green P, McNicholas A, O'Hallahan J: Use of an observational cohort study to estimate the effectiveness of the New Zealand group B meningococcal vaccine in children aged under 5 years. Int J Epidemiol 2009, 38(2):413-418.

12. Halperin SA, Bettinger JA, Greenwood B, Harrison LH, Jelfs J, Ladhani SN, Mclntyre P, Ramsay ME, Safadi MA: The changing and dynamic epidemiology of meningococcal disease. Vaccine 2012, 30(Suppl 2):B26-B36.

13. Vyse A, Wolter JM, Chen J, Ng T, Soriano-Gabarro M: Meningococcal disease in Asia: an under-recognized public health burden. Epidemiol Infect 2011, 139:967-985.

14. Lee SO, Ryu SH, Park SJ, Ryu J, Woo JH, Kim YS: Meningococcal disease in the republic of Korea army: incidence and serogroups determined by PCR. J Korean Med Sci 2003, 18(2):163-166.

15. Raja NS, Parasakthi N, Puthucheary SD, Kamarulzaman A: Invasive meningococcal disease in the University of Malaya Medical Centre, Kuala Lumpur, Malaysia. J Postgrad Med 2006, 52(1):23-29.

16. Robbins JB, Schneerson R, Gotschlich EC, Mohammed I, Nasidi A, Chippaux $J P$, Bernardino L, Maiga MA: Meningococcal meningitis in sub-Saharan Africa: the case for mass and routine vaccination with available polysaccharide vaccines. Bull World Health Organ 2003, 81(10):745-750.

17. Choudhuri D, Huda T, Theodoratou E, Nair H, Zgaga L, Falconer R, Luksic I, Johnson $\mathrm{HL}$, Zhang JS, El Arifeen S, et al: An evaluation of emerging vaccines for childhood meningococcal disease. BMC Publ Health 2011 11(Suppl 3):S29.

18. Harrison LH, Trotter CL, Ramsay ME: Global epidemiology of meningococcal disease. Vaccine 2009, 27(Suppl 2):B51-B63.

19. Anh DD, Kilgore PE, Slack MP, Nyambat B, le Tho H, Yoshida LM, Nguyen $H A$, Nguyen CD, Chong CY, Nguyen D, et al: Surveillance of pneumococcal-associated disease among hospitalized children in Khanh Hoa Province, Vietnam. Clin Infect Dis 2009, 48(Suppl 2):S57-S64.

20. Anh DD, Kilgore PE, Kennedy WA, Nyambat B, Long HT, Jodar L, Clemens JD, Ward J: Haemophilus influenzae type B meningitis among children in Hanoi, Vietnam: epidemiologic patterns and estimates of $\mathrm{H}$. Influenzae type B disease burden. AmJTrop Med Hyg 2006, 74(3):509-515.

21. Kim JS, Jang YT, Kim JD, Park TH, Park JM, Kilgore PE, Kennedy WA, Park E, Nyambat B, Kim DR, et al: Incidence of Haemophilus influenzae type b and other invasive diseases in South Korean children. Vaccine 2004, 22(29-30):3952-3962.

22. Taha MK, Alonso JM, Cafferkey M, Caugant DA, Clarke SC, Diggle MA, Fox A, Frosch M, Gray SJ, Guiver M, et al: Interlaboratory comparison of PCRbased identification and genogrouping of Neisseria meningitidis. J Clin Microbiol 2005, 43(1):144-149.

23. Corless CE, Guiver M, Borrow R, Edwards-Jones V, Fox AJ, Kaczmarski EB: Simultaneous detection of Neisseria meningitidis, Haemophilus influenzae, and Streptococcus pneumoniae in suspected cases of meningitis and septicemia using real-time PCR. J Clin Microbiol 2001, 39(4):1553-1558.

24. Llull D, Lopez R, Garcia E: Characteristic signatures of the lytA gene provide a basis for rapid and reliable diagnosis of Streptococcus pneumoniae infections. J Clin Microbio/ 2006, 44(4):1250-1256.

25. Wilson K: Preparation of genomic DNA from bacteria. Curr Protoc Mol Biol 2001, Chapter 2:Unit 2. 4

26. Fraisier $C$, Stor $R$, Tenebray $B$, Sanson $Y$, Nicolas $P$ : Use of a new single multiplex PCR-based assay for direct simultaneous characterization of six Neisseria meningitidis serogroups. J Clin Microbiol 2009, 47(8):2662-2666.

27. Newcombe RG: Interval estimation for the difference between independent proportions: comparison of eleven methods. Stat Med 1998, 17(8):873-890 
28. Disease trends: decrease in meningococcal group C. http://www. meningitisuk.org/meningitis/disease/surveillance/disease-trends.htm.

29. Cohn AC, MacNeil JR, Harrison LH, Hatcher C, Theodore J, Schmidt M, Pondo T, Arnold KE, Baumbach J, Bennett N, et al: Changes in Neisseria meningitidis disease epidemiology in the United States, 1998-2007: implications for prevention of meningococcal disease. Clin Infect Dis 2009, 50(2):184-191.

30. Luca V, Gessner BD, Luca C, Turcu T, Rugina S, Rugina C, llie M, Novakova E, Vlasich C: Incidence and etiological agents of bacterial meningitis among children $<5$ years of age in two districts of Romania. Eur I Clin Microbiol Infect Dis 2004, 23(7):523-528.

31. Hye Kyung Cho HL, Jin Han K, Kwang Nam K, Dong Soo K, Yun Kyung K, Jung Soo K, Jong-Hyun K, Chang Hwi K, Hwang Min K, Su-Eun P, Sung Hee O, Eun Hee C, Sung Ho C, Young Youn C, Jae Kyun H, Young Jin H, Hoan Jong L, Kyung-Hyo K: The causative organisms of bacterial meningitis in Korean Children in 1996-2005. J Korean Med Sci 2010, 25:895-899.

32. Oberti J, Hoi NT, Caravano R, Tan CM, Roux J: An epidemic of meningococcal infection in Vietnam (southern provinces). Bull World Health Organ 1981, 59(4):585-590.

33. Stein-Zamir C, Abramson N, Zentner G, Shoob H, Valinsky L, Block C: Invasive meningococcal disease in children in Jerusalem. Epidemiol Infect 2008, 136(6):782-789.

34. Dyet KH, Martin DR: Clonal analysis of the serogroup B meningococci causing New Zealand's epidemic. Epidemiol Infect 2006, 134(2):377-383.

35. Tondella ML, Popovic T, Rosenstein NE, Lake DB, Carlone GM, Mayer LW, Perkins BA, The Active Bacterial Core Surveillance Team: Distribution of Neisseria meningitidis serogroup B serosubtypes and serotypes circulating in the United States. J Clin Microbiol 2000, 38(9):3323-3328.

36. Gessner BD, Sutanto A, Linehan M, Djelantik IG, Fletcher T, Gerudug IK, Ingerani, Mercer D, Moniaga V, Moulton LH, et al: Incidences of vaccinepreventable Haemophilus influenzae type $b$ pneumonia and meningitis in Indonesian children: hamlet-randomised vaccine-probe trial. Lancet 2005, 365(9453):43-52

37. Yang L, Shao Z, Zhang X, Xu L, Peng J, Xu X, Liang X, Qi Y, Jin Q: Genotypic characterization of Neisseria meningitidis serogroup $B$ strains circulating in China. J Infect 2008, 56(3):211-218.

38. Zhang X, Shao Z, Yang E, Xu L, Xu X, Li M, Ren J, Zhu Y, Yang F, Liang X, et al: Molecular characterization of serogroup $C$ Neisseria meningitidis isolated in China. J Med Microbiol 2007, 56(Pt 9):1224-1229.

39. Xu Li SZ-j, Gao Y: Surveillance on pathogens of meningococcal meningitis in China, 2004-2006. Institute for Communicable Disease Control and Prevention, Chinese Center for Disease Control and Prevention, Beijing 102206. Chin J Vaccines Immunization 2007, 3.

40. Bae SM, Kang YH: Serological and genetic characterization of meningococcal isolates in Korea. Jpn J Infect Dis 2008, 61(6):434-437.

41. Snape MD, Medini D, Halperin SA, DeTora L, Drori J, Moxon ER: The challenge of post-implementation surveillance for novel meningococcal vaccines. Vaccine 2012, 30(Suppl 2):B67-B72.

42. Falcao MC, Andrade SB, Ceccon ME, Costa Vaz FA: Neonatal sepsis and meningitis caused by Neisseria meningitidis: a case report. Rev Inst Med Trop Sao Paulo 2007, 49(3):191-194.

43. Tinsa F, Jallouli M, Ben Lassouad M, Smaoui H, Brini I, Bousseta K, Bousnina S: Neonatal meningitis by Neisseria meningitidis B. Tunis Med 2008, 86(11):1014-1015.

doi:10.1186/1471-2334-12-310

Cite this article as: Kim et al:: An expanded age range for meningococcal meningitis: molecular diagnostic evidence from population-based surveillance in Asia. BMC Infectious Diseases 2012 12:310

\section{Submit your next manuscript to BioMed Central and take full advantage of:}

- Convenient online submission

- Thorough peer review

- No space constraints or color figure charges

- Immediate publication on acceptance

- Inclusion in PubMed, CAS, Scopus and Google Scholar

- Research which is freely available for redistribution 